\title{
Understanding the Impact of Lifestyle on the Academic Performance of Middle- and High-School Students
}

\author{
Suchithra Rajendran ${ }^{1,2, *} \&$ S. Chamundeswari ${ }^{3}$ \\ ${ }^{1}$ Department of Industrial and Manufacturing Systems Engineering, University of Missouri, \\ Columbia MO 65211, USA \\ ${ }^{2}$ Department of Marketing, University of Missouri, Columbia MO 65211, USA \\ ${ }^{3}$ N.K.T. National College of Education for Women, Chennai-600 005, India \\ *Corresponding author: Department of Industrial and Manufacturing Systems Engineering, \\ University of Missouri, Columbia MO 65211, USA. Tel: 1-573-882-7421. E-mail: \\ RajendranS@missouri.edu
}

Received: June 24, 2019 Accepted: July 17, 2019 Published: July 23, 2019

doi:10.5296/jsr.v10i2.15145 URL: https://doi.org/10.5296/jsr.v10i2.15145

\begin{abstract}
This paper presents a path analysis investigating the direct and indirect influence of lifestyle on academic performance for middle-school and high-school students. The correlation between the following sets of variables are studied: (a) lifestyle and stress; (b) stress and obesity; (c) lifestyle and obesity; (d) lifestyle on academic performance; (e) stress on academic performance; and (f) obesity on academic performance. Adolescent students from 18 schools in India participated in this study. While academic performance is estimated using GPA, questionnaires are used to capture the lifestyle habits of students as well as to assess various forms of stressors such as academic, psychological and health-related. Our results suggest that, a healthier lifestyle is positively correlated to academic performance, while high-stress level has a negative influence. A significant negative relationship is observed between lifestyle and stress, and stress and obesity are observed to be positively related. Obesity, surprisingly, is not a significant predictor of student academic performance for the collected survey data. Our investigation further exposes the need to consider lifestyle in future research.
\end{abstract}

Keywords: Path analysis, Lifestyle, Academic performance, Stress, Obesity, Middle school, High school 


\section{Introduction}

Recent years have witnessed a rapid change in lifestyle due to the availability of the wide range of high-fat and high-calorie foods, telecommunication devices such as smartphones, social media, etc. (Devaraj et al., 2008; Rosenheck, 2008; Al-Nakeeb et al., 2014; Hollywood et al., 2017; Nikolopoulos et al., 2017). According to the World Health Organization (WHO), sedentary lifestyle leads to several factors that cause mortality such as cardiovascular disease, obesity, diabetes, depression and anxiety. González et al. (1999) suggested that one of the key determinants for the growing obesity rates in the Western countries is inactive lifestyle. Similarly, research performed by Ravussin et al. (1994) with Pima Indians made them conclude that obesity is less prevalent among people with a healthier lifestyle. Obesity can, in turn, be a significant predictor of academic performance. Numerous researchers investigate the relationship between the two (e.g., Sabia, 2007; Ding et al., 2009; Krukowski et al., 2009), however, their end conclusions differ based on several factors such as student ethnicity, race, gender and age. Taras et al. (2005) and Kang et al. (2016) observed the negative correlation between body weight and academic performance among adolescents, while Sabia (2007) reports no relationship between the two for non-white students.

Another path to understanding the relationship between lifestyle and academic performance is through stress. Though efforts have been made by researchers to understand the impact of stress on academic performance in several countries across the globe for college students, very limited studies focus on adolescent stressors and their influence on student performance. Struthers et al. (2000) derived the relationship between academic stress, coping and class performance for college students in the United States, and concluded that student stress is inversely related to academic achievement. While Sanders (2001) did not find any relationship between these two variables when he surveyed a dental school in Australia. Clearly, conclusions made by one study cannot be generalized for different settings across the globe. While several scholars have aimed to comprehend the impact of stress on academic performance, studies focusing on the association between lifestyle and stress has been hardly in existence, but it is, however, necessary to consider that due to the recent increase in physical inactivity, which can impact the mental well-being.

In addition to these above-mentioned health-related repercussions, unhealthy lifestyle practiced by children has unfavorable consequences on their academic performance as well. Chiasson and Aubé (2008) criticized the fewer number of studies focusing on the impact of lifestyle on student academic achievements. Nonetheless, poor lifestyle negatively affects the psychological well-being of adolescents, which can sequentially influence student attendance, attention span and academic performance (Bandura, 1997). Despite the fact that dietary behavior has a strong influence on test grades, breakfast consumption among adolescents is declining over time (Rampersaud et al., 2005). Lifestyle habits are interlinked as well. For instance, breakfast-skipping behavior is correlated to smoking (Barker et al., 2000; Keski-Rahkonen et al., 2003; Sjöberg et al., 2003; Rampersaud et al., 2005) and lack of regular exercise (Aarnio et al., 2002; Keski-Rahkonen et al., 2003; Rampersaud et al., 2005). 


\section{Ml Macrothink}

This research, therefore, explores the direct and indirect relationship between lifestyle and academic performance among adolescents in India. First, we sought to explore the relationship between lifestyle and obesity, which influences academic performance. Second, we establish the connection between stress, which is influenced by lifestyle, and academic achievement. The correlation between stress and obesity is also studied. Looking at the relationships between these factors, a path model was developed (conceptual framework given in Figure 1) with elements including lifestyle habits, obesity, stress and academic performance and their associations. Our research aims to hypothesize the following:

- Hypothesis 1: An unhealthy lifestyle will lead to an increase in the stress levels (i.e., a healthy lifestyle will lead to reduced stress)

- Hypothesis 2: An increased stress level leads to obesity

- Hypothesis 3: A negative relationship exists between a healthy lifestyle and obesity

- Hypothesis 4: A healthy lifestyle leads to better academic performance

- Hypothesis 5: An increase in stress level has a negative impact on academic performance

- Hypothesis 6: Obesity leads to the poor academic performance of students

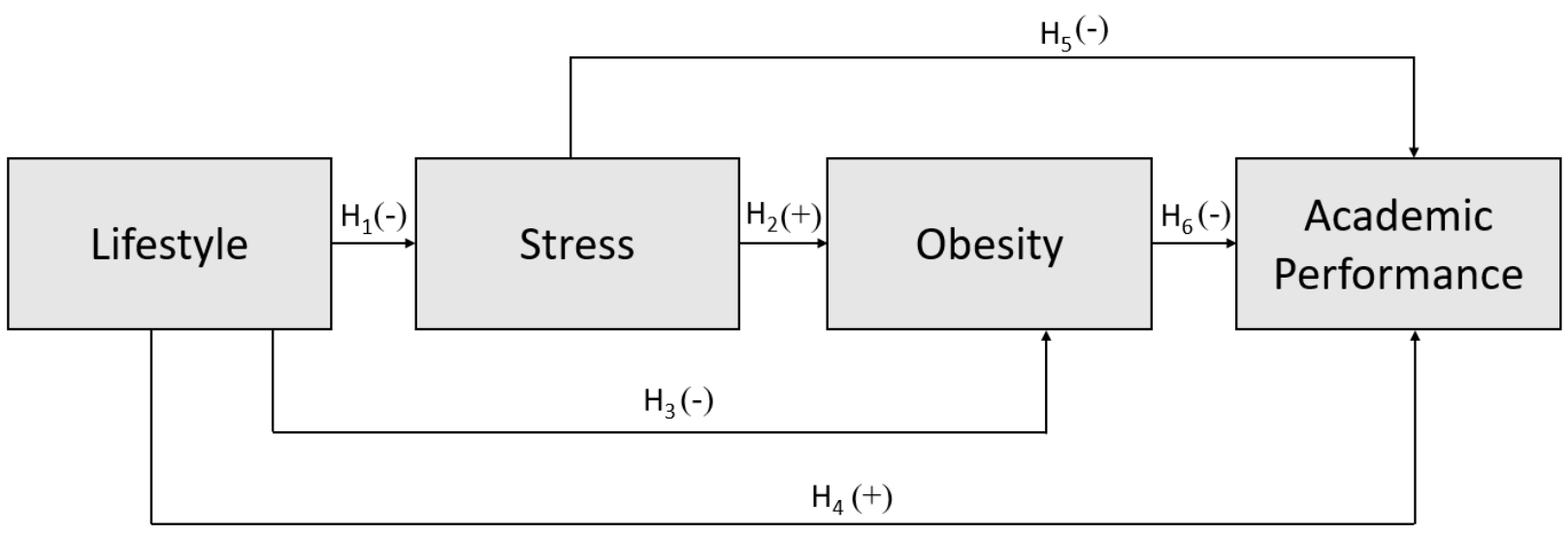

Figure 1. Proposed Conceptual Framework using Path Analysis

\section{Methods}

In this section, we discuss the participants, procedures and measures in detail.

\subsection{Data Collection and Analysis}

Participants were middle- and high-school students from 18 schools in a largely-populated metropolitan city in India. Schools belonged to diversified settings with respect to the type of gender education (i.e., single/mixed gender), medium of education, education board, etc. were chosen for this study. We assessed the academic performance, the key dependent variable in this research, using the grade point average (GPA) for that academic year. As 
these collected data are sensitive, they are stored in a secured location. The principal investigators (PIs) visited all the schools and explained the objectives of this study to the participants. PIs answered all questions and issues raised by the students. Only students, who consented to access their GPA, participated in the study. Participants were asked to fill a pen-and-pencil self-administered questionnaire during their regular class hours, and they were guaranteed of data confidentiality (including their academic performance information).

The data were analyzed using $\mathrm{R}$ statistical software. As discussed earlier, we used the path analysis to examine the association between lifestyle, stress, obesity and academic achievement of students.

\subsection{Procedure}

Path analysis is a series of "layered" multiple regression used to understand the causal relationship between variables. Therefore, the statistical requirement for using regression has to be checked first. We have conducted the preliminary analysis to ensure that the assumptions of linearity, independence, normality and homoscedasticity are not violated. As suggested by Crego et al. (2016), all the variables are standardized (i.e., converted to Z-score) in order to avoid the problem of multi-collinearity prior to conducting the path analysis.

\subsection{Measures}

The survey composed of three sections; one is associated with obtaining control variables, and the other two are research instruments that are used to acquire stress and lifestyle scores. Confounding variables include student demographics, such as age and gender. We have referenced the Holmes and Rahe scale for students developed by Holmes and Rahe (1967) to obtain the student stress level. A list of 43 major stressful life events is presented to students and they mark "yes" or "no" depending on whether they have experienced that event in the past year or not. Each of the 43 events is given a life change unit value, and the cumulative score for all events that were responded as "yes" is used to measure the total stress score of the student. Lifestyle scores were estimated using the FANTASTIC questionnaire (developed by Douglas and Ciliska, 1984), which involved 21 questions investigating varying aspects of life, such as physical activities, sleeping habits, nutrition information. All items are scored in a 5-point Likert scale ( 1 - almost never to 5 - always). Higher scores in this questionnaire indicate a poor lifestyle, whereas lower scores represent a healthier lifestyle.

\section{Results}

A total of 2050 questionnaires were distributed across the 18 schools, and the partially marked surveys (i.e., incomplete), were considered as invalid and eliminated from this study. Following this elimination, we were able to acquire 2001 completely filled valid questionnaires (recovery rate $=97.61 \%$ ), out of which $1016(50.77 \%$ ) were completed by boys (i.e., $n=985$ girls). Kline (1998) recommended the sample size to be at least ten times the number of parameters, and the sample size in our study complies with this suggestion. Among the 2001 filled surveys, $1081(\sim 54 \%)$ were completed by students with an average survey completion time of 45 minutes, while middle school students $(\sim 56 \%)$ specifically took 


\section{Al Macrothink}

Journal of Sociological Research

ISSN 1948-5468

2019, Vol. 10, No. 2

about 65 minutes to fill the entire set of questionnaires. Summary statistics are provided in Table 1.

The 2001 valid respondents on an average aged 14.35 years (SD: 1.48), and ranged between 12 and 20 years. The percentage of students who have impoverished lifestyle was $7.24 \%$, and only about a fourth of the students followed healthy lifestyle habits. A majority of the students lacked physical fitness due to their high pressure of performing well in academics to increase their chances of getting into good universities. Since all the participants of our study are school students, obesity existed in a significantly lower proportion (4.5\%). Unexpectedly, high-level of perceived stress was reported by $59.92 \%$ of the students and only $2.8 \%$ experienced low-stress.

Table 1. Descriptive Data of Key Variables

\begin{tabular}{|c|c|c|}
\hline Student Characteristics & Middle School & High School \\
\hline Age $($ mean \pm SD $)$ & $12.87 \pm 2.74$ & $15.23 \pm 3.10$ \\
\hline Number of students & 1121 & 880 \\
\hline \multicolumn{3}{|l|}{ Gender } \\
\hline - Male (\% of total) & $583(52 \%)$ & $433(49 \%)$ \\
\hline - $\quad$ Female $(\%$ of total $)$ & $538(48 \%)$ & $447(51 \%)$ \\
\hline \multicolumn{3}{|l|}{ Medium of Education } \\
\hline - $\quad$ State Board $(\%$ of total $)$ & $751(67 \%)$ & $607(69 \%)$ \\
\hline - $\quad$ CBSE $(\%$ of total) & $370(33 \%)$ & $273(31 \%)$ \\
\hline \multicolumn{3}{|l|}{ Gender Schools } \\
\hline - $\quad$ Mixed (\% of total) & $807(72 \%)$ & $774(88 \%)$ \\
\hline - $\quad$ Single $(\%$ of total $)$ & $314(28 \%)$ & $106(12 \%)$ \\
\hline
\end{tabular}

Table 2 presents the results of the path analysis. Based on previous studies, we have controlled several variables (such as age, gender, level of student education - i.e., middle- or high-school) across all the regression analyses in our study. In support of hypothesis-1, lifestyle significantly predicted perceived stress (Table 2). The more the students stated that they follow a healthier lifestyle, less the perceived stress. As anticipated, results proved that stress increases with age and level of education. In addition, we found that girl students underwent more stress compared to their counterparts.

Students' stress was included in the model to analyze factors contributing to obesity. Both lifestyle and obesity yielded significant beta coefficients. Healthier lifestyle led to less 
obesity (i.e., a negative relationship is observed) while a positive association was observed between stress and obesity. In other words, obese students reported higher perceived stress level. Consistent with hypothesis-3, lifestyle had a statistically significant positive relationship with academic achievement directly and indirectly through stress. Surprisingly, an insignificant association was found between obesity and academic performance.

In path analysis, the path coefficients represent the relative importance of the variables. We can see from Table 2 that the path coefficient from stress to academic performance is the largest and takes the value of -0.32 . In other words, about $32 \%$ of the variation in academic performance is explained by stress. The relative influence of lifestyle on obesity and stress on obesity are more or less the same with path coefficients of -0.22 and 0.20 respectively. We can also observe that $11 \%$ of the variability in stress is explained by lifestyle, and $9 \%$ of the variability in academic performance is explained by lifestyle. Though the direct path coefficient value of lifestyle to academic performance is low (0.09), the total contribution is substantially higher (0.38).

Table 2. Data Table Showing Path Coefficient and $p$-values

\begin{tabular}{ccccc}
\hline Construct & Path & Construct & Standardized path coefficient & $\boldsymbol{p}$-value \\
\hline Stress & $\longleftarrow$ & Lifestyle & -0.11 & $<0.01$ \\
Obesity & $\longleftarrow$ & Stress & 0.20 & $<0.001$ \\
Obesity & $\longleftarrow$ & Lifestyle & -0.22 & $<0.001$ \\
Academic Performance & $\longleftarrow$ & Lifestyle & 0.09 & $<0.05$ \\
Academic Performance & $\longleftarrow$ & Stress & -0.32 & $<0.001$ \\
Academic Performance & $\longleftarrow$ & Obesity & -0.02 & 0.12 \\
\hline
\end{tabular}

Table 3. Result of Hypothesis Testing

\begin{tabular}{cll}
\hline Hypothesis & & \multicolumn{1}{c}{ Statement } \\
\hline$H_{1}$ & An unhealthy lifestyle will lead to an increase in the stress levels & Supported \\
$H_{2}$ & An increased stress levels leads to obesity & Supported \\
$H_{3}$ & A negative relationship exist between a healthy lifestyle and obesity & Supported \\
$H_{4}$ & A healthy lifestyle leads to better academic performance & Supported \\
$H_{5}$ & An increase in stress level has a negative impact on academic performance & Supported \\
$H_{6}$ & Obesity leads to the poor academic performance of students & Rejected \\
\hline
\end{tabular}

From Tables 2 and 3, we can interpret that lifestyle has both direct and indirect influence (only through stress) on academic performance. In other words, a healthier lifestyle leads to the academic excellence of students (supporting hypothesis-4). Stress negatively predicted academic performance (supporting hypothesis-5), which is supported the finding of Stewart et al. (1999), Struthers et al. (2000) and Shah et al. (2010). Poor lifestyle habits increase the risk of obesity (supporting hypothesis-3). However, contradicting to the claims made by 
Taras et al. (2005) and Kang et al. (2016), we did not observe any relationship between obesity and academic performance, rejecting hypothesis-6. As expected, lifestyle is found to be negatively linked to stress, which supports hypothesis-1. The results of the hypothesis testing are summarized in Table 3.

\section{Discussion}

The objective of this research was to study the relationship between lifestyle and academic performance. By including other important variables that are connected to both lifestyle and academic achievement, this research aimed to present a more complex view of the process. Path analysis was used to achieve this study's objective by controlling for several factors such as age, gender and level of education. Most of the paths were significant as hypothesized.

Supportive of our first hypothesis, unhealthy lifestyle activities were linked to stressful student life. In other words, a negative correlation existed between lifestyle habits and perceived stress level. Al-Nakeeb et al. (2014) criticized the lifestyle changes in the last couple of decades. Stress was observed to increase with age assuring the claims made by several studies (e.g., Hamarat et al., 2001; Hampel and Petermann, 2006). Consistent with Petersen et al. (1991) and Hampel and Petermann (2006), our results also showed that girls perceive more stress than boys. Girls were found to watch more television than boys and sleep for less number of hours. As suggested in prior studies (Maloney et al., 1989; Croll et al., 2001), our findings also suggested that girls eat more nutritious food because of their desire to lose weight. Contradicting to the claims made by Kaplan et al. (1991) and Brannon (2016), participants in our study insignificantly vary by gender with respect to outlook in life.

In regards to our third hypothesis, obesity is negatively correlated with lifestyle habits. Numerous investigations such as those found in Ravussin et al. (1994) and González et al. (1999) suggested that one of the key determinants for the growing obesity rates is inactive lifestyle. Interestingly, in our study, we found that obesity was more prevalent among girls than in boys. Prior researchers have aimed to understand the relationship between stress and appetite regulation (e.g., Nguyen-Rodriguez et al., 2003; Torres and Nowson, 2007; Sinha and Jastreboffde, 2013). Food consumption, in turn, affects BMI and waist circumference (Monti et al., 2006; Konttinen et al., 2010). van Jaarsveld et al. (2012) investigated the prospective association between stress and waist circumference and BMI in more than 4000 adolescents. Their study reported that perceived stress was associated with higher BMI and waist circumference.

Our fourth hypothesis is associated with the main focus of our study, which is to understand the relationship between lifestyle and academic performance. Partial lifestyle habits and their impact on student GPA has been studied. For example, Rampersaud et al. (2005) stated that dietary behavior has a strong influence on test grades, but regardless of that, breakfast consumption among adolescents is declining over time (Rampersaud et al., 2005). Lifestyle habits are interlinked as well. For instance, breakfast-skipping behavior is correlated to 
smoking (Barker et al., 2000; Keski-Rahkonen et al., 2003; Sjöberg et al., 2003; Rampersaud et al., 2005) and lack of regular exercise (Aarnio et al., 2002; Keski-Rahkonen et al., 2003; Rampersaud et al., 2005). We found that a healthier lifestyle leads to academic excellence of students. Stress negatively predicted academic performance, which supported the findings of Struthers et al. (2000) and Shah et al. (2010). Contradicting to the claims made by Taras et al. (2005) and Kang et al. (2016), we did not observe any relationship between obesity and academic performance.

One of the major limitations in our study is that we use convenience sampling to select participants for this study, and hence they might not be representing a broader population. Specifically, our study involves students in a metropolitan city, and the results might not be generalized for rural area adolescents. Kline (1998) and Lepp et al. (2014) recommend the sample size to be at least ten times the number of parameters, and the sample size in our study complies with this suggestion. Nevertheless, a sample of 2500 questionnaires might limit the power of regression analysis. Another drawback of this study is capturing perceived stress by conducting surveys rather than to use tools to measure stress directly. With the development in technology and the introduction of human stress monitoring devices (such as small watches), stress can be directly recorded by the survey interviewer. Moreover, surveys might lead to memory error, order effects and social desirability bias (Crego et al., 2016). However, we conducted the survey very close to their term exam, responses with respect to perceived stress score will be most likely accurate.

A third limitation of this research is that our sample had a low variability in body weight, mainly because of the fact that obesity is less prevalent among youths in India. This might not be a global scenario. Several studies have observed significant obesity prevailing in several countries such as Bahrain, Brazil, China, Russia, Saudi Arabia and the United States (see Wang et al., 2002; Al-Rukban, 2003; Al-Sendi et al., 2003; Ogden et al., 2006; Ogden et al., 2014). Moreover, our convenience sampling resulted in exceptionally few female students who were tobacco users. Therefore, diversified sample with respect to obesity and tobacco users is required to generalize the results.

Despite the limitations of this research, five of the six hypotheses were supported. Future studies can consider looking at intervention programs to improve the lifestyle and dietary habits of adolescents. Moreover, the impact of occupation of parents might affect lifestyle habits among students and their academic performance. Therefore, conducting a study controlling these variables can be a potential scope of improvement. Finally, the consistency of the results can be checked with conducting the study with other well-established questionnaires from the literature can be used to obtain stress level and lifestyle scores.

\section{Conclusions}

The findings in this study provide a better understanding of the relationships between lifestyle, obesity, stress and academic performance. Only very limited research focus on understanding the relationship between lifestyle habits and academic performance, and our 
research provides a path analysis framework to study the direct and indirect associations between the two variables. Our findings show that lifestyle significantly predicts academic performance, both directly and indirectly. While stress has a negative association with academic performance, obesity seems not to affect student exam scores. Stress is positively related to obesity. This study proves the need to pursue interventional programs to promote awareness about healthy lifestyle habits.

One of the major limitations in our study is that we use convenience sampling to select participants for this study, and hence they might not be representing a broader population. Specifically, our study involves students in a metropolitan city, and the results might not be generalized for rural area adolescents. Moreover, a sample of 2500 questionnaires might limit the power of regression analysis. Another drawback of this study is capturing perceived stress through surveys rather than to use tools to measure stress directly. With the development in technology and the introduction of human stress monitoring devices (such as small watches), stress can be directly recorded by the survey interviewer. We also see that our sample had a low variability in body weight, mainly because of the fact that obesity is less prevalent among youths in India. This might not be a global scenario.

As a future research, studies can consider looking at intervention programs to improve the lifestyle and dietary habits of adolescents. Moreover, the impact of occupation of parents might affect lifestyle habits among students and their academic performance. Therefore, conducting a study controlling these variables can be a potential scope of improvement. Finally, the consistency of the results can be checked with conducting the study with other well-established questionnaires from the literature can be used to obtain stress level and lifestyle scores.

\section{Acknowledgement}

The authors would like to profusely thank the reviewers for their valuable feedback that helped us to improve the earlier version of the paper.

\section{References}

Aarnio, M., Winter, T., Kujala, U., \& Kaprio, J. (2002). Associations of health related behaviour, social relationships, and health status with persistent physical activity and inactivity: a study of Finnish adolescent twins. British Journal of Sports Medicine, 36(5), 360-364. https://dx.doi.org/10.1136\%2Fbjsm.36.5.360

Ahn, J. (2011). The effect of social network sites on adolescents' social and academic development: Current theories and controversies. Journal of the American Society for information Science and Technology, 62(8), 1435-1445. https://doi.org/10.1002/asi.21540

Al-Nakeeb, Y., Dodd, L., Lyons, M., Collins, P., \& Al Nuaim, A. A. (2014). A cluster 
analysis of lifestyle and health habits of youth from two geographically and culturally diverse countries. Open J. Prev. Med., 4, 193-203. https://doi.org/10.4236/ojpm.2014.44025

Al-Nuaim, A. A., Al-Nakeeb, Y., Lyons, M., Al-Hazzaa, H., Nevill, A., Collins, P., \& Duncan, M. J. (2012). The prevalence of physical activity and sedentary behaviours relative to obesity among adolescents from Al-Ahsa, Saudi Arabia: Rural vs. urban variations. Journal of Nutrition and Metabolism, 2012, 417589. https://doi.org/10.1155/2012/417589

Al-Rukban, M. O. (2003). Obesity among Saudi male adolescents in Riyadh, Saudi Arabia. Saudi medical journal, 24(1), 27-33.

Al-Sendi, A. M., Shetty, P., \& Musaiger, A. O. (2003). Prevalence of overweight and obesity among Bahraini adolescents: a comparison between three different sets of criteria. European journal of clinical nutrition, $47(3), \quad 41$. https://doi.org/10.1038/sj.ejcn.1601560

Alwagait, E., Shahzad, B., \& Alim, S. (2015). Impact of social media usage on students academic performance in Saudi Arabia. Computers in Human Behavior, 51, 1092-1097. https://doi.org/10.1016/j.chb.2014.09.028

Bandura A. (1997). Self - Efficacy: The Exercise of Control. W. H. Freeman and Company, New York.

Barker, M., Robinson, S., Wilman, C., \& Barker, D. J. P. (2000). Behaviour, body composition and diet in adolescent girls. Appetite, 35(2), 161-170. https://doi.org/10.1006/appe.2000.0345

Brannon, L. (2016). Gender: psychological perspectives. Routledge.

Chou, W. Y. S., Hunt, Y. M., Beckjord, E. B., Moser, R. P., \& Hesse, B. W. (2009). Social media use in the United States: implications for health communication. Journal of medical Internet research, 11(4), e48. https://dx.doi.org/10.2196\%2Fjmir.1249

Crego, A., Carrillo-Diaz, M., Armfield, J. M., \& Romero, M. (2016). Stress and academic performance in dental students: the role of coping strategies and examination-related self-efficacy. Journal of dental education, 80(2), 165-172.

Croll, J. K., Neumark-Sztainer, D., \& Story, M. (2001). Healthy eating: what does it mean to adolescents? Journal of nutrition education, 33(4), 193-198.

Devaraj, S., Wang-Polagruto, J., Polagruto, J., Keen, C. L., \& Jialal, I. (2008). High-fat, energy-dense, fast-food-style breakfast results in an increase in oxidative stress in $\begin{array}{llll}\text { metabolic } & \text { syndrome. } & \text { Metabolism, } & \text { 87(6), }\end{array}$ https://doi.org/10.1016/j.metabol.2008.02.016

Ding, W., Lehrer, S. F., Rosenquist, J. N., \& Audrain-McGovern, J. (2009). The impact of poor health on academic performance: New evidence using genetic markers. Journal of 
health economics, 28(3), 578-597. https://doi.org/10.1016/j.jhealeco.2008.11.006

Douglas, W., \& Ciliska, D. (1984). Lifestyle assessment: development and use of the fantastic checklist. Can Family Physician, 30, 1527-32.

Hamarat, Dennis Thompson, Karen M. Zabrucky, Don Steele, Kenneth B. Matheny \& Ferda Aysan, E. (2001). Perceived stress and coping resource availability as predictors of life satisfaction in young, middle-aged, and older adults. Experimental Aging Research, 27(2), 181-196. https://doi.org/10.1080/036107301750074051

Hampel, P., \& Petermann, F. (2006). Perceived stress, coping, and adjustment in adolescents. Journal of Adolescent Health, 38(4), 409-415. https://doi.org/10.1016/j.jadohealth.2005.02.014

Hollywood, L., Surgenor, D., Reicks, M., McGowan, L., Lavelle, F., Spence, M., ... \& Dean, M. (2017). Critical review of behaviour change techniques applied in intervention studies to improve cooking skills and food skills among adults. Critical reviews in food science and nutrition, 1-14. https://doi.org/10.1080/10408398.2017.1344613

Holmes, T. H., \& Rahe, R. H. (1967). The social readjustment rating scale. Journal of psychosomatic research, 11(2), 213-218. https://doi.org/10.1016/0022-3999(67)90010-4

Kang, Yang Wha \& Jong-Hyock Park. (2016). Does Skipping Breakfast and Being Overweight Influence Academic Achievement Among Korean Adolescents? Osong public health and research perspectives, 7(4), 220-227. https://doi.org/10.1016/j.phrp.2016.05.004

Kaplan, R. M., Anderson, J. P., \& Wingard, D. L. (1991). Gender differences in health-related quality of life. Health Psychology, 10(2), 86.

Keski-Rahkonen, A., Kaprio, J., Rissanen, A., Virkkunen, M., \& Rose, R. J. (2003). Breakfast skipping and health-compromising behaviors in adolescents and adults. $\begin{array}{llll}\text { European journal of clinical nutrition, } & 57(7), \quad 842 .\end{array}$ https://doi.org/10.1038/sj.ejcn.1601618

Konttinen, H., Männistö, S., Sarlio-Lähteenkorva, S., Silventoinen, K., \& Haukkala, A. (2010). Emotional eating, depressive symptoms and self-reported food consumption. A population-based study. Appetite, 54(3), 473-479. https://doi.org/10.1016/j.appet.2010.01.014

Krukowski, R. A., Smith West, D., Philyaw Perez, A., Bursac, Z., Phillips, M. M., \& Raczynski, J. M. (2009). Overweight children, weight-based teasing and academic performance. International Journal of Pediatric Obesity, 4(4), 274-280. https://doi.org/10.3109/17477160902846203

Maloney, M. J., McGuire, J., Daniels, S. R., \& Specker, B. (1989). Dieting behavior and eating attitudes in children. Pediatrics, 84(3), 482-489.

Monti, V., Carlson, J. J., Hunt, S. C., \& Adams, T. D. (2006). Relationship of ghrelin and 
leptin hormones with body mass index and waist circumference in a random sample of adults. Journal of the American Dietetic Association, 106(6), 822-828. https://doi.org/10.1016/j.jada.2006.03.015

Moorhead, S. A., Hazlett, D. E., Harrison, L., Carroll, J. K., Irwin, A., \& Hoving, C. (2013). A new dimension of health care: systematic review of the uses, benefits, and limitations of social media for health communication. Journal of medical Internet research, 15(4), e85. https://doi.org/10.2196/jmir.1933

Nguyen-Rodriguez, S. T., Chou, C. P., Unger, J. B., \& Spruijt-Metz, D. (2008). BMI as a moderator of perceived stress and emotional eating in adolescents. Eating behaviors, 9(2), 238-246. https://doi.org/10.1016/j.eatbeh.2007.09.001

Nikolopoulos, H., Mayan, M., MacIsaac, J., Miller, T., \& Bell, R. C. (2017). Women's perceptions of discussions about gestational weight gain with health care providers during pregnancy and postpartum: a qualitative study. BMC pregnancy and childbirth, 17(1), 97. https://doi.org/10.1186/s12884-017-1257-0

Ogden, C. L., Carroll, M. D., Curtin, L. R., McDowell, M. A., Tabak, C. J., \& Flegal, K. M. (2006). Prevalence of overweight and obesity in the United States, 1999-2004. Jama, 295(13), 1549-1555.

Ogden, C. L., Carroll, M. D., Kit, B. K., \& Flegal, K. M. (2014). Prevalence of childhood and adult obesity in the United States, 2011-2012. Jama, 311(8), 806-814. https://doi.org/10.1001/jama.295.13.1549

Petersen, A. C., Sarigiani, P. A., \& Kennedy, R. E. (1991). Adolescent depression: Why more girls?. Journal of youth and adolescence, 20(2), 247-271. https://doi.org/10.1007/BF01537611

Rosenheck, R. (2008). Fast food consumption and increased caloric intake: a systematic review of a trajectory towards weight gain and obesity risk. Obesity Reviews, 9(6), 535-547. https://doi.org/10.1111/j.1467-789X.2008.00477.x

Rouis, S., Limayem, M., \& Salehi-Sangari, E. (2011). Impact of Facebook Usage on Students' Academic Achievement: Role of self-regulation and trust. Electronic Journal of Research in Educational Psychology, 9(3), 961-994.

Sabia, J. J. (2007). The effect of body weight on adolescent academic performance. Southern Economic Journal, 73(4), 871-900. https://www.jstor.org/stable/20111933

Shah, M., Hasan, S., Malik, S., \& Sreeramareddy, C. T. (2010). Perceived stress, sources and severity of stress among medical undergraduates in a Pakistani medical school. BMC medical education, 10(1), 2. https://doi.org/10.1186/1472-6920-10-2

Sinha, R., \& Jastreboff, A. M. (2013). Stress as a common risk factor for obesity and

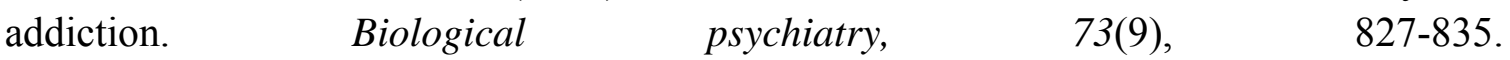
https://doi.org/10.1016/j.biopsych.2013.01.032 
Sjöberg, A., Hallberg, L., Höglund, D., \& Hulthen, L. (2003). Meal pattern, food choice, nutrient intake and lifestyle factors in The Göteborg Adolescence Study. European journal of clinical nutrition, 57(12), 1569. https://doi.org/10.1038/sj.ejcn.1601726

Stewart, S. M., Lam, T. H., Betson, C. L., Wong, C. M., \& Wong, A. M. P. (1999). A prospective analysis of stress and academic performance in the first two years of medical school. Medical education, 33(4), 243-250. https://doi.org/10.1046/j.1365-2923.1999.00294.x

Struthers, C. W., Perry, R. P., \& Menec, V. H. (2000). An examination of the relationship among academic stress, coping, motivation, and performance in college. Research in higher education, 41(5), 581-592. https://www.jstor.org/stable/40196403

Taras, H., \& Potts - Datema, W. (2005). Obesity and student performance at school. Journal of School Health, 75(8), 291-295. https://doi.org/10.1111/j.1746-1561.2005.00040.x

Torres, S. J., \& Nowson, C. A. (2007). Relationship between stress, eating behavior, and obesity. Nutrition, 23(11-12), 887-894. https://doi.org/10.1016/j.nut.2007.08.008

Van Jaarsveld, C. H., Fidler, J. A., Steptoe, A., Boniface, D., \& Wardle, J. (2009). Perceived stress and weight gain in adolescence: a longitudinal analysis. Obesity, 17(12), 2155-2161. https://doi.org/10.1038/oby.2009.183

Wang, Y., Monteiro, C., \& Popkin, B. M. (2002). Trends of obesity and underweight in older children and adolescents in the United States, Brazil, China, and Russia. The American journal of clinical nutrition, 75(6), 971-977. https://doi.org/10.1093/ajcn/75.6.971

WHO. (2010). "Physical Inactivity a Leading Cause of Disease and Disability, Warns WHO." World Health Organization, World Health Organization, 8 Dec. 2010, www.who.int/mediacentre/news/releases/release23/en/.

Ziebland, S. U. E., \& Wyke, S. (2012). Health and illness in a connected world: how might sharing experiences on the internet affect people's health? The Milbank Quarterly, 90(2), 219-249. https://doi.org/10.1111/j.1468-0009.2012.00662.x

\section{Copyright Disclaimer}

Copyright for this article is retained by the author(s), with first publication rights granted to the journal.

This is an open-access article distributed under the terms and conditions of the Creative Commons Attribution license (http://creativecommons.org/licenses/by/3.0/). 